\title{
PERANCANGAN APLIKASI SISTEM PENJUALAN DAN PEMBELIAN BUAH PADA TOKO BUAH LALI MUNJUL
}

\author{
Maria Usava $^{1}$, Thomas Afrizal ${ }^{2}$, Nurfidah Dwitiyanti ${ }^{3}$ \\ Program Studi Teknik Informatika, Fakultas Teknik dan Ilmu Komputer, \\ Universitas Indraprasta PGRI \\ Jalan Raya Tengah No 80, Kelurahan Gedong, Pasar Rebo, Jakarta Timur \\ mariausava@gmail.com ${ }^{1}$, thomztaurus.it@gmail.com², nurfidah.pulungan@ gmail.com ${ }^{3}$
}

\begin{abstract}
Abstrak
Pemanfaatan teknologi informasi dapat memberikan nilai tambah bari para usahawan. Namun, banyak usahawan yang masih awam terhadap teknologi informasi, padahal dengan menggunakan teknologi informasi dapat memberikan kemudahan dan keuntungan dalam usaha mereka. Toko Buah Lali Munjul merupakan salah satu bidang usaha yang masih awam terhadap penggunaan teknologi. Rumusan permasalahan pada penelitian ini adalah bagaimana membuat sistem penjualan dan pembelian buah yang efektif dan efisien untuk membantu proses penjualan dan pembelian buah pada Toko Buah Lali Munjul dan bagaimana proses pembuatan laporan pada Toko Buah Lali Munjul agar efektif dan efisien. Tujuan dari penelitian ini adalah untuk membuat rancangan aplikasi sistem penjualan dan pembelian buah pada Toko Buah Lali Munjul agar efektif dan efisien, serta membuat laporan penjualan, laporan pembelian, laporan buah rusak, dan laporan stok buah yang lebih rinci untuk memberikan data akurat pada Toko Buah Lali Munjul secara periodik. Metode penelitian yang digunakan adalah Metode Research and Development (R\&D) dan teknik pengumpulan data yang digunakan pada penelitian ini meliputi observasi, wawancara, dan studi literatur. Hasil dari penelitian ini adalah dengan diterapkannya aplikasi sistem penjualan dan pembelian buah pada Toko Buah Lali Munjul, dapat mempermudah dan membantu menata pengelolaan data penjualan dan pembelian buah menjadi lebih efektif dan efisien.
\end{abstract}

Kata Kunci: Aplikasi, Penjualan dan Pembelian, Java, MySQL

\begin{abstract}
The use of information technology can provide added value to entrepreneurs. However, many entrepreneurs are still lay against information technology, even though using information technology can provide convenience and advantages in their business. Toko Buah Lali Munjul is one of the business fields that are still common against the use of technology. The formulation of the problem in this study is how to create an effective and efficient fruit sales and purchase system to help the process of selling and buying fruit Toko Buah Lali Munjul Store and how the process of making reports at Toko Buah Lali Munjul Store to be effective and efficient. The purpose of this study was to design the application of the sale and purchase system of fruit at Toko Buah Lali Munjul Store to be effective and efficient, as well as create sales reports, purchase reports, broken fruit reports, and more detailed fruit stock reports to provide accurate data to Toko Buah Lali Munjul Store periodically. The research methods used are the Research and Development $(R \& D)$ method and the data collection techniques used in this study include observation, interview, and literature studies. The result of this research is that the application of the fruit sales and purchase system application at Toko Buah Lali Munjul Store, can facilitate and help organize the management of sales and fruit purchase data to be more effective and efficient
\end{abstract}

Keywords: Application, Sales and Purchasing, Java, MySQL

\section{PENDAHULUAN}

Perkembangan teknologi informasi saat ini sudah semakin pesat dalam berbagai bidang, salah satunya adalah bidang usaha atau bisnis. Teknologi diartikan sebagai kegiatan manusia dalam merencanakan dan menciptakan benda-benda yang bernilai praktis (Abriana, 2017). Sedangkan informasi adalah sekumpulan data atau fakta yang telah diproses dan diolah sedemikian rupa sehingga menghasilkan sesuatu yang bisa dipahami dan memberikan manfaat bagi penerimanya (Putra, 2020). Sehingga teknologi informasi dapat diartikan dengan berbagai teknologi dan aplikasi komputer untuk menyimpan, mempelajari/menganalisa, mengambil, memanipulasi data dan/atau 
informasi dalam bentuk kata-kata/suara, dokumen dan/atau gambar-gambar serta mengirimkan/mendistribusikan, menerima dan mengolah/memproses kembali sesuai dengan kebutuhan pemakai/pengguna informasi secara elektronik (Bagaskoro, 2019). Toko Buah Lali Munjul adalah sebuah toko yang bergerak di bidang usaha atau bisnis yang menjual berbagai jenis buah-buahan yang masih awam terhadap penggunaan teknologi informasi. Kegiatan yang dilakukan sama seperti kegiatan toko buah pada umumnya, yaitu melakukan pembelian di pasar lalu menjualnya kembali. Setiap hari Toko Buah Lali Munjul melakukan kegiatan bisnis secara manual sehingga Toko Buah Lali Munjul mengalami kendala dalam pengolahan informasi yang dibutuhkan, misalnya dalam pengolahan data stok buah, buah rusak, pencatatan transaksi penjualan dan pembelian, serta sering terjadi kesalahan dalam pembuatan laporannya.

Rumusan masalah dari penelitian ini adalah bagaimana membuat sistem penjualan dan pembelian buah yang efektif dan efisien untuk membantu proses penjualan dan pembelian buah pada Toko Buah Lali Munjul, bagaimana proses pembuatan laporan penjualan, laporan pembelian, laporan buah rusak, dan laporan stok buah pada Toko Buah Lali Munjul agar efektif dan efisien.Tujuan dari penelitian ini adalah membuat rancangan aplikasi sistem penjualan dan pembelian buah pada Toko Buah Lali Munjul agar efektif dan efisien, membuat laporan penjualan, laporan pembelian, laporan buah rusak, dan laporan stok buah yang lebih rinci untuk memberikan data akurat pada Toko Buah Lali Munjul secara periodik. Manfaat yang didapat dari hasil penelitian ini adalah membantu mempermudah semua kegiatan yang berjalan di Toko Buah Lali Munjul, seperti penjualan buahbuahan, pembelian buah-buahan, pengelolaan data stok buah, dan pembuatan laporannya.

\section{PENELITIAN RELEVAN}

Penelitian yang relevan dengan penelitian ini adalah penelitian yang dilakukan oleh (Hartanto\& Mulyawan, 2018) dengan judul Perancangan Aplikasi E-Commerce Jakarta Fruit Market. Hasil dari penelitian tersebut adalah dengan adanya aplikasi dapat menyediakan informasi mengenai produk serta memudahkan pelanggan untuk membeli produk. Penelitian serupa juga dilakukan oleh (Setiawan\&Irawan, 2017) dengan judul Perancangan Aplikasi Penjualan Buah Mang Udin Menggunakan Bahasa Pemrograman Visual Basic. Hasil penelitian tersebut adalah dengan adanya aplikasi dapat memudahkan penjualan dalam penghitungan jumlah beli dan meminimalkan kekeliruan yang dapat merugikan penjual. Perbedaan penelitian sebelumnya dengan penelitian ini adalah aplikasi yang digunakan dalam merancang aplikasi menggunakan NetBeans 8.2 dengan basis data MySQL dan persamaan dari penelitian sebelumnya dengan penelitian ini adalah untuk mempermudah dan membantu proses penjualan dan pembelian buah agar efektif dan efisien.

\section{METODE PENELITIAN}

\section{Metode Penelitian}

Metode penelitian yang digunakan adalah Metode Research and Development ( $\& \& D)$. Metode Research and Development $(R \& D)$ adalah sebuah metode penelitian yang digunakan untuk menghasilkan suatu produk tertentu dan kemudian menguji keefektifan dari produk tersebut (Hanafi, 2017). Pada dasarnya penelitian Research and Development $(R \& D)$ memiliki karakteristik adanya produk yang dihasilkan dari suatu penelitian. Produk yang dihasilkan diawai dari analisis kebutuhan dari lokasi penelitian (Alfindasari, 2014). Adapun langkah-langkah dalam menghasilkan produk tersebut diawali dari analisis kebutuhan dari lokasi penelitian, perancangan, penerapan, dan pemeliharaan.

\section{Teknik Pengumpulan Data}

Metode pengumpulan data yang dilakukan oleh peneliti untuk mendapatkan data-data serta informasi untuk mendukung hasil dari penelitian ini antara lain: 
a. Observasi

Pengumpulan data-data yang dibutuhkan dalam penelitian dengan melakukan pengamatan secara langsung ke tempat penelitian untuk mengamati kegiatan yang dilakukan pada Toko Buah Lali Munjul.

b. Wawancara

Metode wawancara ditunjukan kepada orang-orang yang berkecimpung langsung maupun tidak langsung dalam proses pengelolaan pada Toko Buah Lali Munjul, guna mencari penjelasan pada saat observasi.

c. Studi Literatur

Pengumpulan data yang bersumber dari buku-buku serta catatan selama perkuliahan, data tersebut diambil berdasarkan kaitan topik yang berhubungan sebagai bahan penunjang.

\section{Langkah-Langkah Pengembangan Sistem}

Pengembangan penelitian ini menggunakan metode Research and Development $(R \& D)$.

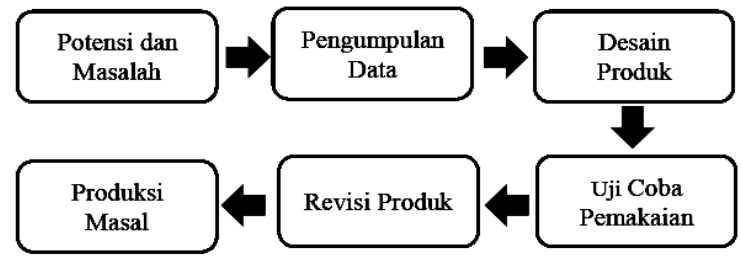

Gambar 1. Langkah-Langkah Research and Development $(R \& D)$

Langkah-langkah metode Research and Development $(R \& D)$ adalah sebagai berikut:

a. Potensi dan Masalah

Potensi adalah sebagai segala sesuatu yang bila didayagunakan akan memiliki nilai tambah pada produk yang diteliti. Sedangkan masalah adalah penyimpangan antara yang diharapkan dengan yang terjadi.

b. Mengumpulkan Informasi dan Studi Literatur

Mengumpulkan berbagai informasi dan studi literatur yang dapat digunakan sebagai bahan untuk perencanaan produk tertentu yang diharapkan dapat mengatasi masalah tersebut.

c. Desain Produk

Produk didesain agar dapat mengatasi masalah yang ada. Desain produk harus diwujudkan dalam bentuk gambar, untuk memudahkan membuatnya.

d. Uji Coba Pemakaian

Setelah pengujian terhadap produk berhasil, produk diujicobakan pada kelompok yang lebih luas.

e. Revisi Produk

Perbaikan produk apabila ditemukan kelemahan pada uji coba skala luas.

f. Pembuatan Produk Masal

Produk yang sudah final kemudian diproduksi secara masal agar dapat digunakan secara optimal.

\section{HASIL DAN PEMBAHASAN}

\section{Diagram Alir Data (DAD) Sistem Berjalan}

Diagram Alir Data menggambarkan suatu arus dari data sistem, penggunaan Diagram Alir Data (DAD) sangat membantu untuk memahami sistem secara logika, terstruktur, dan jelas (Setiawan, 2016). Diagram konteks merupakan diagram yang terdiri dari suatu proses dan menggambarkan ruang lingkup suatu sistem (Prasetyo, 2013). 


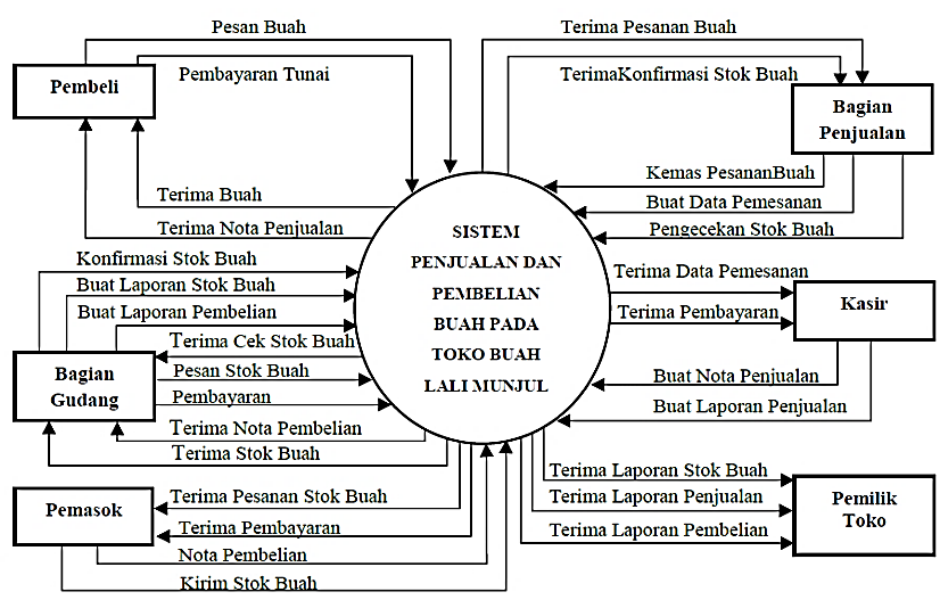

Gambar 2. Diagram Konteks Sistem Berjalan

\section{Analisis Permasalahan}

Dari hasil penelitian yang dilakukan maka peneliti dapat menganalisa permasalahan yang ada pada sistem penjualan dan pembelian buah pada Toko Buah Lali Munjul, yaitu:

a. Pembuatan laporan masih dilakukan secara manual sehingga sering terjadi kesalahan dan proses pembuatan membutuhkan waktu yang cukup lama.

b. Sulitnya membuat laporan karena sering terjadi kehilangan berkas-berkas dan tempat penyimpanan yang kurang memadai sehingga sulit untuk proses pengambilan keputusan oleh pemilik toko.

c. Sering mengalami kesalahan dalam menghitung dan kurang keakuratan dalam perhitungan transaksi penjualan, sehingga dapat menimbulkan kerugian pada pendapatan penjualan.

d. Belum adanya laporan mengenai kerugian akibat kerusakan buah dari pembelian stok buah yang harus dikalkulasi agar Toko Buah Lali Munjul mendapat laporan keuntungan dan kerugian secara terperinci.

\section{Alternatif Penyelesaian Masalah}

Berdasarkan permasalahan yang terdapat pada sistem penjualan dan pembelian buah yang berjalan pada Toko Buah Lali Munjul, berikut uraian dari penyelesaian masalah:

a. Diperlukan adanya suatu sistem yang terkomputerisasi dan dapat menggantikan sistem lama untuk pengolahan data penjualan, pembelian, dan stok buah agar dapat memudahkan dan tidak memerlukan banyak waktu dan tenaga dalam pembuatan laporan yang diserahkan kepada pemilik toko, dan laporan bisa dibuat kapan saja jika diperlukan.

b. Dengan adanya sistem yang terkomputerisasi diharapkan dapat meminimalkan kesalahan perhitungan dan kurang keakuratan yang terjadi pada sistem lama.

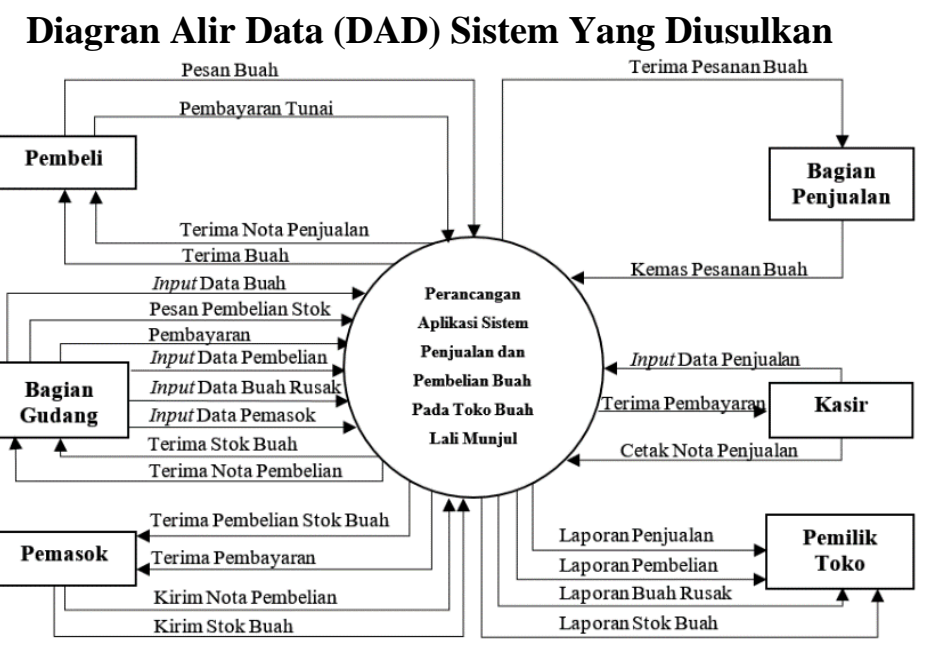

Gambar 3. Diagram Konteks Sistem yang Diusulkan 


\section{Entity Relationship Diagran (ERD)}

Entity Relationship Diagram (ERD) merupakan suatu model yang menjelaskan hubungan antar data di dalam database berdasarkan objek dasar data yang mempunyai hubungan antar relasi. Entity Relationship Diagram (ERD) digunakan untuk mencerminkan model database: struktur dari entitas dan relasi di antara entitas tersebut (A. Prasetyo \& Susanti, 2016).

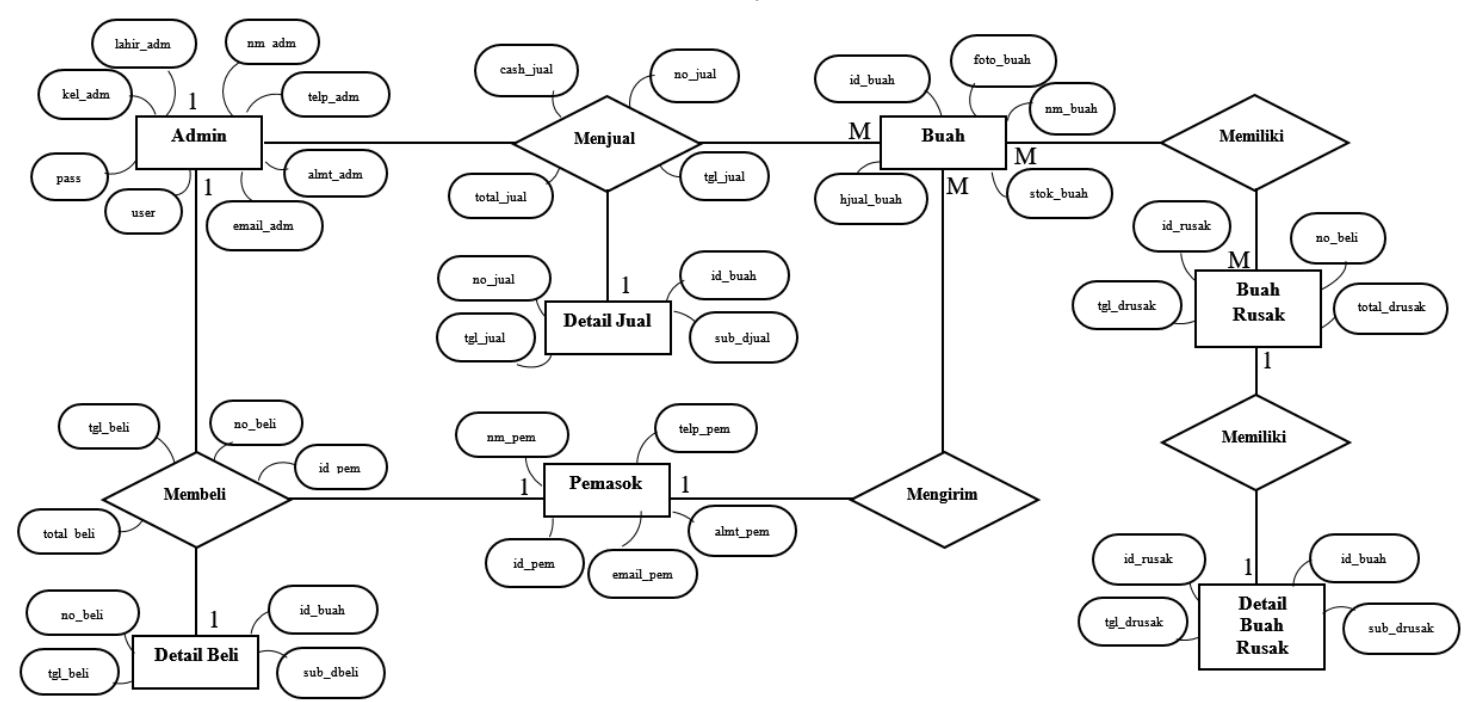

Gambar 4. Entity Relationship Diagram (ERD)

\section{Tampilan Perancangan Aplikasi Sistem Penjualan Dan Pembelian Buah Pada Toko Buah} Lali Munjul

Peneliti membuat aplikasi ini dengan menggunakan Netbeans edisi 8.2 dengan basis data MySQL aplikasi XAMPP. Berikut tampilan aplikasi pada Toko Buah Lali Munjul.

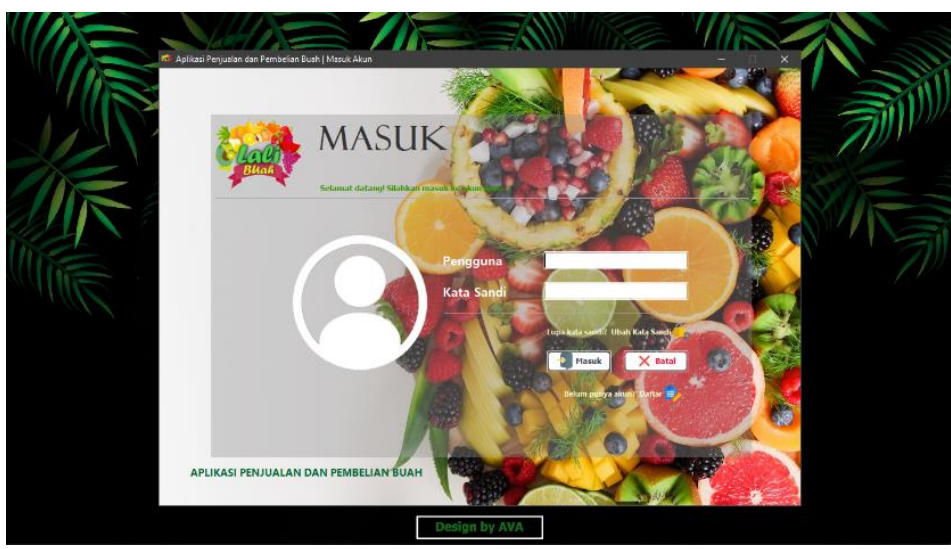

Gambar 5. Tampilan Layar Form Masuk

Tampilan layar form masuk terdiri dari kolom pengguna dan kata sandi, terdapat tombol masuk dan tombol batal, serta terdapat dua link, yaitu link ubah kata sandi dan link daftar. Apabila admin ingin masuk ke dalam aplikasi, maka harus mengisi pengguna dan kata sandi yang sudah tersimpan di dalam database kemudian tekan tombol masuk. 


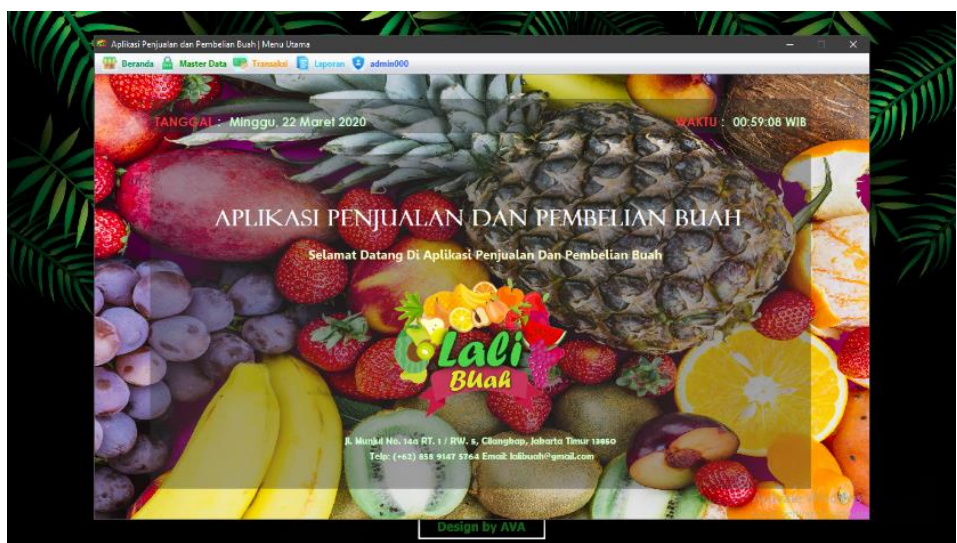

Gambar 6. Tampilan Layar Menu Utama

Menu utama terdiri dari beberapa sub menu yaitu:

a. Menu Beranda, untuk kembali ke halaman menu utama.

b. Menu Master Data, terdiri dari beberapa sub menu antara lain:

1. Data Buah, berisi data buah yang ada pada Toko Buah Lali Munjul.

2. Data Pemasok, berisi data pemasok yang menjual buah ke Toko Buah Lali Munjul.

3. Data Buah Rusak, berisi data buah rusak dari pembelian buah.

c. Menu Transaksi, dalam menu ini terdapat dua sub menu, yaitu:

1. Penjualan Buah, berisi data buah yang akan dijual ke pembeli seperti kode penjualan, tanggal penjualan, kode buah, nama buah, jenis buah, harga jual, total pembayaran, uang pembayaran, dan kembalian yang dapat dicetak ke nota penjualan untuk diberikan ke pembeli.

d. Menu Laporan, dalam menu ini terdiri dari beberapa sub menu keluaran antara lain:

1. Laporan Data Stok Buah, berisi rekap data buah yang dapat dicetak.

2. Laporan Penjualan, berisi rekap data penjualan yang dapat dicetak sesuai periode dan dapat menampilkan grafik penjualan berdasarkan harian, mingguan, bulanan, dan tahunan.

3. Laporan Pembelian, berisi rekap data pembelian yang dapat dicetak sesuai periode.

4. Laporan Buah Rusak, berisi rekap data buah rusak yang dapat dicetak sesuai periode.

e. Menu Admin, berisi sub menu keluar untuk menuju ke menu masuk aplikasi.

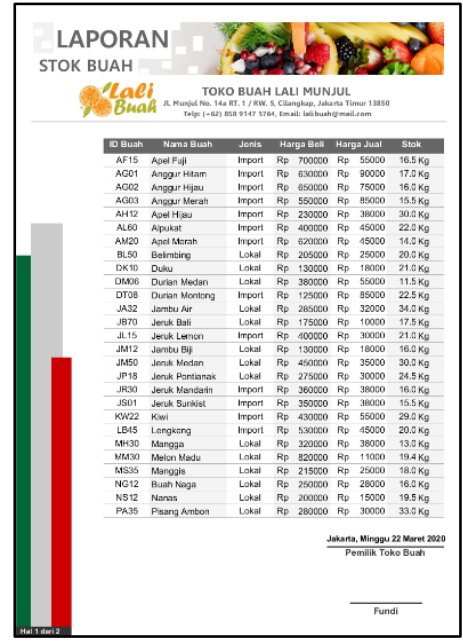

Gambar 7. Tampilan Keluaran Laporan Stok Buah

Tampilan di atas merupakan hasil cetak dari laporan stok buah yang kemudian akan diserahkan kepada pemilik toko. 


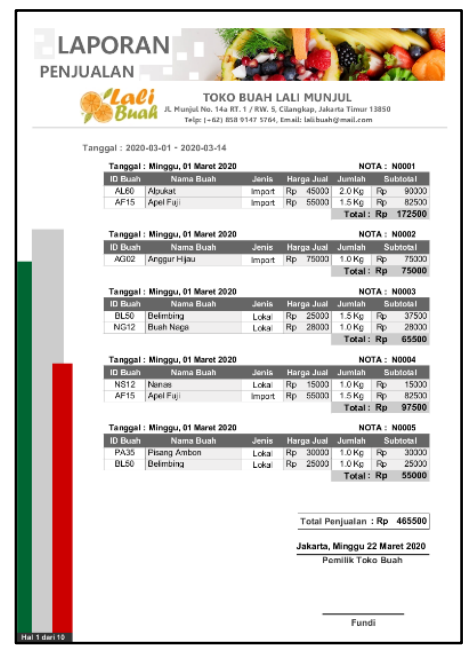

Gambar 8. Tampilan Keluaran Laporan Penjualan

Tampilan di atas merupakan hasil cetak dari laporan penjualan buah yang kemudian akan diserahkan kepada pemilik toko.

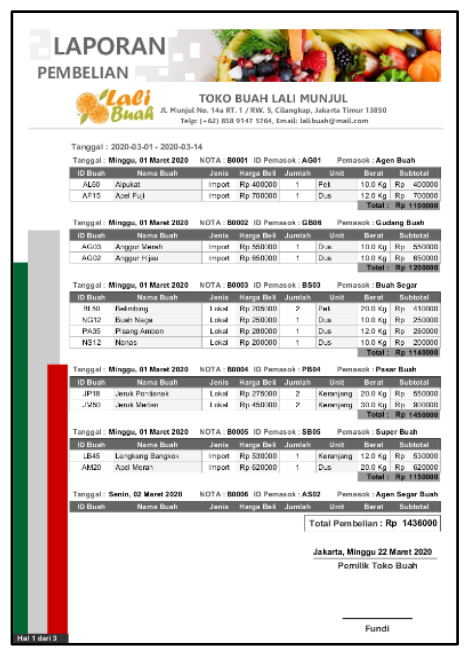

Gambar 9. Tampilan Keluaran Laporan Pembelian

Tampilan di atas merupakan hasil cetak dari laporan pembelian buah yang kemudian akan diserahkan kepada pemilik toko.

\section{SIMPULAN}

Dengan dibuatnya sistem terkomputerisasi penjualan dan pembelian buah yang dirancang pada penelitian ini, kiranya dapat diterapkan untuk menggantikan sistem manual dengan harapan dapat mengatasi kelemahan atau kekurangan yang selama ini dihadapi oleh Toko Buah Lali Munjul. Adapun kesimpulan dari hasil penelitian ini adalah sebagai berikut:

1. Proses pengelolaan data penjualan dan pembelian buah sebelumnya masih kurang efektif, sehingga peneliti merancang aplikasi sistem penjualan dan pembelian buah dalam bentuk aplikasi desktop berbasis Java untuk membantu proses penjualan dan pembelian buah pada Toko Buah Lali Munjul dan mempermudah dalam menata pengelolaan data buah agar lebih efektif dan efisien.

2. Hasil pengolahan data yang diperoleh dari sistem ini adalah laporan stok buah, laporan penjualan, laporan pembelian, dan laporan buah rusak. Laporan yang diperoleh berasal dari data yang tersimpan di dalam database. Data tersebut tersimpan secara aman dan dapat dipanggil 
atau dicetak sebagai laporan secara periodik sesuai kebutuhan sehingga menghasilkan laporan penjualan, laporan pembelian, laporan buah rusak, dan laporan stok buah yang efektif dan efisien.

\section{DAFTAR PUSTAKA}

Abriana, A. (2017). Teknologi Pengolahan dan Pengawetan Ikan. Makasar: Celebes Media Perkasa.

Alfindasari, D. (2014). Langkah-langkah Melakukan R\&D (Research and Development). Diambil 1 Juni 2020, dari https://www.eurekapendidikan.com/2014/12/karakteristik-r-research-and-development.html

Bagaskoro. (2019). Pengantar Teknologi Informatika dan Komunikasi Data. Yogyakarta: Deepublish Publisher.

Hanafi. (2017). Konsep Penelitian R \& D Dalam Bidang Pendidikan. Saintifika Islamica: Jurnal Kajian Keislaman, 4(2), $129-150$.

Hartanto, Ery Dewayani, B. M. (2018). Perancangan Aplikasi E-Commerce Jakarta Fruit Market, 6, 85-91. Diambil dari https://journal.untar.ac.id/index.php/jiksi/article/view/2634/1643

Prasetyo, A., \& Susanti, R. (2016). Sistem Informasi Penjualan Berbasis Web Pada PT. Cahaya Sejahtera Sentosa Blitar. Jurnal Ilmiah Teknologi Informasi Asia, 10(2), 1-16.

Prasetyo, M. A. (2013). Pembuatan Sistem Informasi Penjualan Buah Di Toko Buah Melon Wangi Berbasis Java. Sekolah Tinggi Manajemen Informastika dan Komputer Amikom Yogyakarta.

Putra. (2020). Fungsi, Konsep Dasar \& Jenis Jenis Informasi. Diambil 30 April 2020, dari https://salamadian.com/pengertian-informasi/

Setiawan, H. (2016). Contoh DFD/DAD Diagram Alir Data Sistem Informasi Apotik. Diambil 1 Mei 2020, dari https://www.hendrisetiawan.com/2015/01/contoh-dfd-apotik.html

Setiawan, R., \& Irawan, D. (2017). Perancangan Aplikasi Penjualan Buah Mang Udin Menggunakan Bahasa Pemrograman Visual Basic. Journal of Chemical Information and Modeling, 5. https://doi.org/10.1017/CBO9781107415324.004 